\title{
Commonplace
}

\section{Things to Remember}

\author{
Sarah Kearns, Catherine Ahearn
}

Published on: Dec 20, 2021

DOI: $10.21428 / 6 \mathrm{ffd} 8432.785 \mathrm{be} 05 \mathrm{c}$

License: Creative Commons Attribution 4.0 International License (CC-BY 4.0). 
Everyone's least favorite holiday song is "12 Days of Christmas," right? It goes on for too long, gets stuck in your head, and the only good part is the "five golden rings" line simply because its rhythmically distinct cadence seems to push you toward musical exuberance whether you like it or not. So, in the name of making our own rules in a newsletter we also made up for a publication we helped found, we've decided, wellwe're just going to stop at 5. Keep reading to remember some of the thoughtful, punchy, and memorable content that graced the digital pages of the Commonplace this year. We're not going to make you sing, but you're welcome to.

\section{Visit the web version of this article to view interactive content.}

\section{All together now...}
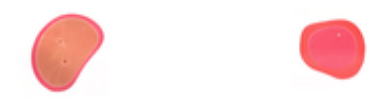

\section{5 | Golden rings / Feast of things}

Even though we shared many more than the traditional "five things," we recently experimented with our newsletter to have components thought of by a whole organization rather than just one person. It was so much fun to put together and think that it expresses the personalities behind the products we work on, and I hope that this practice becomes more common.

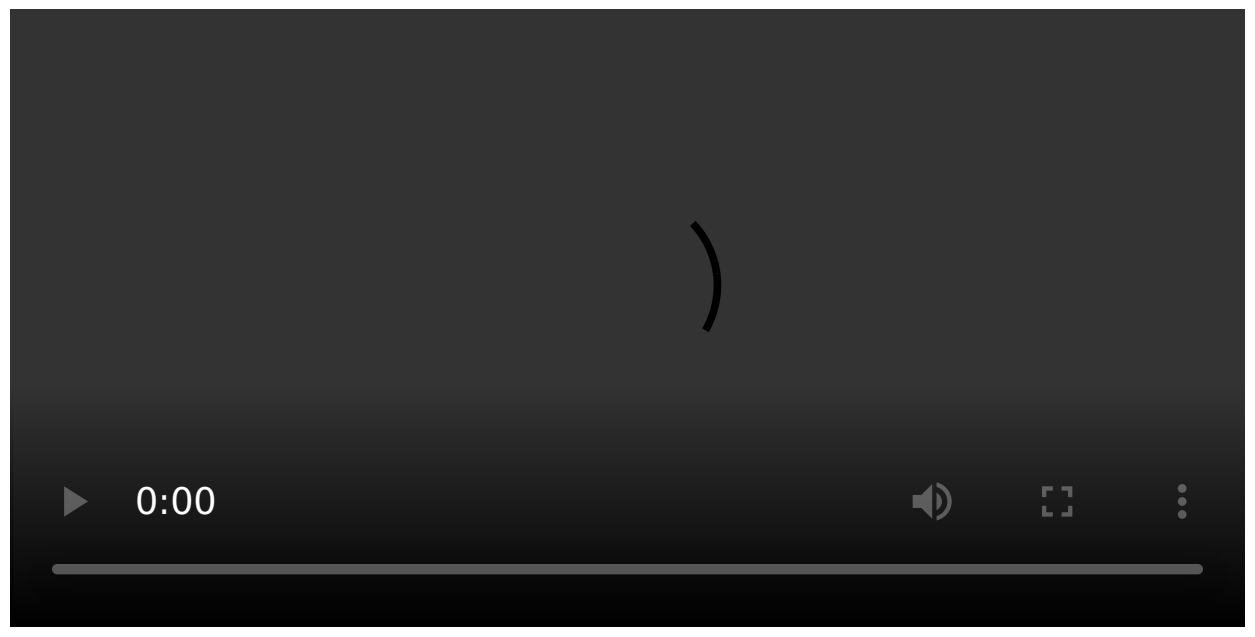




\section{4 | Calling birds / Calls to action}

Much of the goal of the Commonplace is to share provocative and interesting ideas that spark action or at least a different perspective. While many pieces do this, these four highlight the range of ideas and actions that we can take on multiple levels: creating community-based design for teachers and libraries, democratizing soil research tools, identifying opportunities to support BIPOC in open scholarship, and publishing in non-traditional ways as a graduate student.

Click the white circles to go to the articles.

\section{Visit the web version of this article to view interactive content.}

\section{3 | French hens / Podcasts}

In the attempts to have non-text-based content become more normalized, we've started an audio series! So far, we're only at three, but it's been exciting to hear the thoughtful voices of the people making waves. And if you have an idea or want to be on a podcast with us, feel free to reach out.

Click the white circles to go to the podcast.

\section{Visit the web version of this article to view interactive content.}

\section{2 | Turtle doves / New series}

As we noted in the end of year wrap, some of the biggest work and impact that we had on Commonplace was through the series. These collections of articles and audio were responses to continuing publishing company consolidations, and libraries trying to balance institutional and economic sustainability with supporting open access experimentation. In responding to these events and questions, we had a lot of discussion and ideas for restructuring business models and infrastructure to support the changes we want to see happen. 


\section{Visit the web version of this article to view interactive content.}

\section{Visit the web version of this article to view interactive content.}

\section{1 | Partridge in a pear tree / Research study on trickery}

"This is an interesting time to start analyzing and unpacking trust," Sinders et al. state in their research report looking at design patterns that facilitate and weaponize trust and create harassment in platform and communications technology. In this report, both journalists and designers were surveyed to understand how different design elements generate trust in digital media.

What facilitates or designs trust? It's repeated consistency and transparency within the tools as well as clear and consistent responses to users about the harassment they face. To create better products, platforms need to unpack what transparency means in design, and that does not simply mean open sourcing code, it means explaining what a product is doing when and why, and offering opt in versus opt out provisions. In essence, consistency and transparency can be thought of as trust building blocks or trust scaffolding for products. 


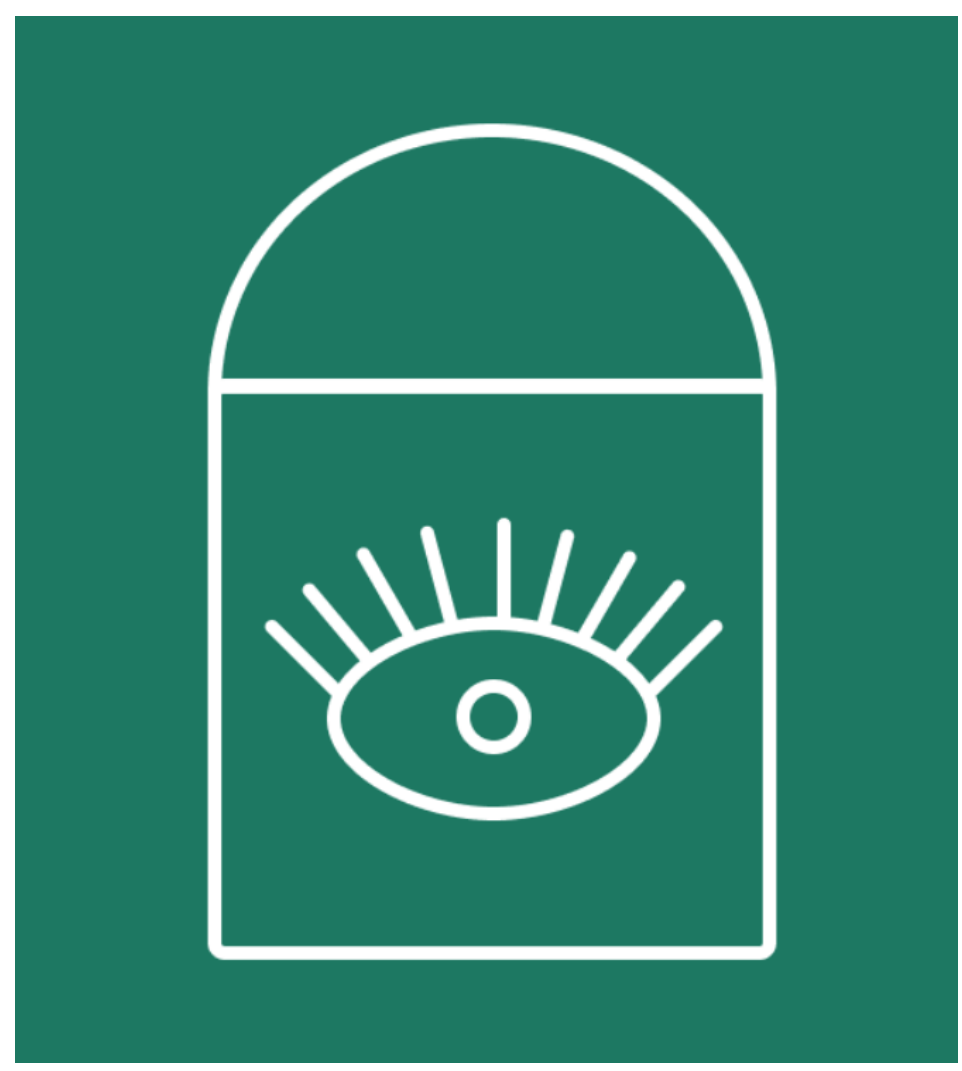

- commonplace editors 